\title{
An In Vitro Assessment of Cariogenic and Erosive Potential of Pediatric Liquid Medicaments on Primary Teeth: A Comparative Study
}

\author{
Tejaswi Singana ${ }^{1}$, Nelamakanahalli Kempaiah Suma ${ }^{2}$
}

\section{Abstract}

Aim: To compare the cariogenic and erosive potential of seven commonly prescribed pediatric liquid medicaments (PLMs) by pediatricians in Kempegowda Institute of Medical Sciences, Bengaluru. The selected medicaments are:

- Syp paracetamol (antipyretic).

- Syp amoxicillin-clavulanate (antibiotic).

- Syp cetirizine (antihistamine).

- Syp dextromethorphan (antitussive).

- Syp salbutamol (antiasthmatic).

- Syp phenytoin (anticonvulsant).

- Syp multivitamin (nutritional supplement).

Materials and methods:

- Quantitative endogenous sucrose estimation: Lane-Eynon volumetric copper reduction method was used for the estimation.

- Endogenous $\mathrm{pH}$ estimation: The endogenous $\mathrm{pH}$ was measured using a digital $\mathrm{pH}$ meter at $10 \%$ dilution.

- Quantification of endogenous erosive potential: few caries and restoration-free, exfoliated or extracted primary teeth were utilized to produce $1-1.5 \mathrm{~g}$ of enamel powder. A $50 \mathrm{mg}$ of enamel powder was then added to $1 \mathrm{~mL}$ of individual PLM. The mixtures were maintained for three-time intervals, 1 minute, 10 minutes, and 8 hours. The samples were then prepared for the estimation of calcium using Inductively Coupled Plasma Mass Spectrometry.

Results: Sucrose was seen in all the PLMs except amoxicillin-clavulanate. Calcium was found to be present in all the PLMs except cetirizine. The highest calcium dissolution was seen within Syp salbutamol and the least with Syp paracetamol.

Conclusion: Syp phenytoin can be regarded as medicament with the highest cariogenic potential and Syp salbutamol with the highest erosive potential and Syp paracetamol with the lowest cariogenic and erosive potential among the compared and tested PLMs.

Clinical significance: Considering syrups that have high cariogenic and erosive potential, greater knowledge about the detrimental effects of these drugs should direct us to evolve effective programs to alert parents to follow proper oral hygiene practices or to search for alternative drugs void of such detrimental effects.

Keywords: Calcium dissolution, Cariogenic potential, Erosive potential, Pediatric liquid medicament, pH, Sucrose.

International Journal of Clinical Pediatric Dentistry (2020): 10.5005/jp-journals-10005-1824

\section{INTRODUCTION}

Dental caries is one of the most common chronic diseases worldwide. This is caused due to prolonged complex interaction between acid-producing bacteria and fermentable carbohydrates with host factors including teeth and saliva playing a role. ${ }^{1}$ It is mostly related to the consumption of sweets in the form of chocolates and biscuits. However, people are unaware of the hidden added sugars in many pediatric liquid medicaments (PLMs) which also is a major reason for dental caries formation in children. ${ }^{2}$

Medications are prescribed for various ailments by pediatricians and physicians. Different routes of administration include oral, rectal, nasal, sublingual, cutaneous, and parenteral routes. Out of these, the most common and oldest administration mode is oral route. ${ }^{3}$ Oral medications like pills or capsules are impractical with children even when they are coated to mask the bitter tastes since children are too young to swallow them. ${ }^{4}$ Hence, syrups, the medications in liquid form are the most endorsed in children.

\footnotetext{
1,2 Department of Pediatric Dentistry, Vokkaligara Sangha Dental College and Hospital, Bangaluru, Karnataka, India

Corresponding Author: Tejaswi Singana, Department of Pediatric Dentistry, Vokkaligara Sangha Dental College and Hospital, Bengaluru, Karnataka, India, Phone: +91 9740872504, e-mail: teja.dare23@gmail. com

How to cite this article: Singana T, Suma NK. An In Vitro Assessment of Cariogenic and Erosive Potential of Pediatric Liquid Medicaments on Primary Teeth: A Comparative Study. Int J Clin Pediatr Dent 2020;13(6):595-599.
}

\section{Source of support: Nil}

Conflict of interest: None

They are widely available and easily acceptable by both parents and children. ${ }^{2}$ The pharmaceutical industry uses sucrose, in large quantities as it acts as a preservative, an antioxidant, a solvent, a demulcent, and a bulking agent. ${ }^{4}$ 
Dental erosion is characterized by loss of tooth structure as a result of chemical dissolution by acids. This is irreversible and occurs without the involvement of bacteria. This may also combine with mechanical activities like abrasion, attrition along with various intrinsic or extrinsic factors. ${ }^{4}$

Sucrose is a non-toxic sweetening agent and free from the aftertaste. It is commonly utilized since it is cheap, non-hygroscopic, easily processable, and available in various pure, dry, physically, and chemically stable forms in different particle sizes. Along with the addition of sugars, surplus acids are also added to these PLMs to act as buffering agents. These acids are responsible for controlling tonicity and ensure the drug's physiological compatibility. ${ }^{4}$

Any change in the balance between sugars and weaker acids may compromise the integrity of dental tissue. To date, there are sparse studies about sugars and the acidic nature of PLMs and their quantification. This study aims mainly at the evaluation of commercially available PLMs for their cariogenic and erosive nature.

\section{Materials and Methods}

Enamel powder was prepared by utilizing exfoliated or extracted primary teeth, which are devoid of caries or restorations, which were collected from hospitals and clinics. Seven PLMs are selected for this study, which are most commonly prescribed by consulting pediatricians through a questionnaire in Kempegowda Institute of Medical Sciences, Bengaluru. Pediatric liquid medicaments used were as given in Table 1. For the selected seven PLMs, sucrose, $\mathrm{pH}$, and calcium dissolution potential were calculated.

\section{Endogenous Quantitative Sucrose Estimation}

Volumetric copper reduction-based Lane-Eynon method was utilized to estimate the concentration of sucrose endogenously. ${ }^{5}$ Two grams of glucose standards were measured and were made to $100 \mathrm{~mL}$. Ten grams of individual PLM was weighed accurately into a $200 \mathrm{~mL}$ volumetric flask. One hundred milliliters of Milli-Q water was added and mixed thoroughly for complete dissolution. With the Milli-Q water, the solution is made up to the mark and this is called the stock solution. $13.856 \mathrm{~g}$ of copper sulfate was added to $200 \mathrm{~mL}$ distilled water and this was called solution A. Solution B was prepared by adding $69.2 \mathrm{~g}$ of potassium sodium tartrate tetrahydrate with $10 \mathrm{~g}$ of sodium hydroxide and made up to 200 $\mathrm{mL}$ by adding it in distilled water. Equal volumes of solutions $A$ and B were mixed to get Fehling's solution.

\section{Glucose(a)}

A stock solution of $100 \mathrm{~mL}$ was taken in a burette and using boiling conditions, the Fehling's infusion was titrated. Using the equation below, free glucose $\%$ was estimated using the quantity of solution

Table 1: PLMs used in the study

\begin{tabular}{lll}
\hline Number & Pediatric liquid medicament & Generic name \\
\hline 1 & Antipyretic & Paracetamol \\
2 & Antibiotic & Amoxicillin, clavulanate \\
3 & Antihistamine & Cetirizine \\
4 & Antitussive & Dextromethorphan \\
5 & Antiasthmatic & Salbutamol \\
6 & Anticonvulsant & Phenytoin \\
7 & Nutritional supplement & Multivitamins \\
\hline
\end{tabular}

used $(\mathrm{mL})$ for the titration of Fehling's solution. We will call this glucose(a):

$$
\text { Glucose }(\%)=3.905 / 2 \times V^{-1.0251} / P \times 10
$$

$V$-volume of sample solution ( $\mathrm{mL}), P$-amount of sample (g).

\section{Glucose(b)}

One hundred milliliters of stock suspension were transferred into a beaker and using $1 \mathrm{~mL} \mathrm{HCl}(32 \%)$ the solution is acidified. Using a water bath $\left(98-102^{\circ} \mathrm{C}\right)$, the solution is then heated for 40 minutes for accelerated sucrose hydrolysis. Using sodium hydroxide (40\% wt/ volume), the solutions were counterpoised after cooling. According to the previously mentioned procedure, the concentration of glucose (glucose(b)) is calculated by titrating the Fehling's infusion using the PLM sample. The estimation of sucrose concentration (SC) was arrived at by the difference of glucose concentrations of the sample after corrosive reversal (glucose(b)) and the value determined about the control (glucose(a)). This can be stated in the form of the below equation:

$$
\text { Sucrose }(\%)=\text { Glucose }(b)-\text { Glucose }(a)
$$

All the PLMs readings were investigated in threefold.

\section{Endogenous pH Estimation}

With the help of a digital $\mathrm{pH}$ meter at $10 \%$ dilution, the endogenous $\mathrm{pH}$ estimation of PLMs was done. The $\mathrm{pH}$ meter was aligned by utilizing a cradle arrangement of $\mathrm{pH} \mathrm{4,} \mathrm{7,} \mathrm{and} 10$ (by supported standard solution). Readings were noted in threefold. ${ }^{5}$

\section{Endogenous Erosive Potential QuANTIFICATION}

1-1.5 gm of enamel powder was obtained using 16 deciduous teeth. Teeth were mesiodistally sliced using a diamond disk. Dentin was removed using a round diamond bur. Using a mortar and a pestle, a fine powder was obtained by grinding the remaining of the enamel shells. The particle size of the resultant powder was then standardized using sieve no. $85 .^{5}$

Enamel powder weighing $50 \mathrm{mg}$ individually was added to the crucible which already contained individual PLM of $1 \mathrm{~mL}$. The mixture was mixed by swirling and they were maintained for threetime intervals which are 1 minute, 10 minutes, and 8 hours. After placing the blends for the said time span, using centrifugation at 5,000 rpm for 10 minutes, the undissolved enamel powder was eliminated. ${ }^{5} 1 / 2 \mathrm{~mL}$ of the supernatant was transferred to the digesting vessel of Microwave digestor (Make: Anton Parr Multiwave Go) $0.5 \mathrm{~mL}$ of nitric acid (Suprapure) was added and the program was set on the multiwave Go. The clear solutions were then transferred to the tubes for Inductively Coupled Plasma Mass Spectrometry (ICP-MS) measurement.

Simultaneously, individual PLM was weighed into the digesting vessel of a microwave digestor $0.5 \mathrm{~mL}$ of nitric acid was added and the program was set on the multiwave Go. The clear solutions were then transferred to the tubes of ICP-MS for measurement. This gives the inherent calcium present in the individual samples. A series of calcium standards were prepared $(1,2,5,10$, and 25 parts per billion (Ppb)) from calcium stock solution 1,000 Parts per million (Ppm) (Make: Merck NIST Traceable). A linearity curve is plotted by the software in the ICP-MS and the individual PLM with and without 
treatment was aspirated and concentrations were calculated by the software from the calibration curve.

\section{RESULTS}

Values obtained by the measurement of three parameters were subjected to statistical analysis and the following results were obtained. Except for amoxicillin-clavulanate, all the other PLMs had sucrose. The highest concentration of sucrose was seen in Syp phenytoin $48.5 \pm 0.41$ (Table 2).

Acidic $\mathrm{pH}$ was observed for Syp multivitamin $4.03 \pm 0.10$, Syp salbutamol $4.24 \pm 0.04$, Syp dextromethorphan $4.30 \pm 0.09$, Syp amoxicillin-clavulanate $4.54 \pm 0.15$, Syp cetirizine $4.67 \pm 0.14$, and Syp phenytoin $4.77 \pm 0.12$. Basic $\mathrm{pH}$ was depicted for Syp paracetamol $6.07 \pm 0.13$ (Table 3).

Apart from cetirizine, all the other PLMs contained calcium. The highest level of calcium was noted in Syp amoxicillinclavulanate $480 \mathrm{Ppb}$ and least which is 0 in cetirizine. Calcium dissolution was recorded at three-time intervals. Most noteworthy calcium dissolution was observed with Syp salbutamol at 3,050 $\mathrm{Ppb}$ and the least with Syp paracetamol at $720 \mathrm{Ppb}$ at the end of 8 hours (Table 4). Statistical correlation between $\mathrm{pH}$ and calcium dissolution potential of PLMs was done using Pearson correlation coefficient test $(r)$ and $p$ values were statistically non-significant (Table 5).

\section{Discussion}

Pediatric liquid medicaments have a long history of use in the field of medicine. ${ }^{2}$ Systemic administration of these drugs includes various routes among which the oral route is the oldest and well-known administration mode. ${ }^{3}$ Syrups are most prescribed in children, and easily acceptable by parents and children. ${ }^{2}$

Children's medicines contain sugars specifically to mask the unpleasant taste accompanied by the active ingredients. ${ }^{3}$ Although these medicines are necessary for being healthy, some added inactive ingredients present may be linked to harmful dental effects like dental caries and dental erosion. ${ }^{6}$

Sucrose concentrations in liquid pediatric medicines were shown to be ranging from 3.7 to $67.0 \%$ by weight from the recent studies done by Passoso et al. ${ }^{7}$ Also, some studies on pediatric medicines reported very high SC (80\%) which was higher compared with ice creams (15.1\%) and soft drinks (4.3\%). ${ }^{6}$ American Academy of Pediatric Dentistry's (AAPD's), Caries Risk Assessment tool (CAT)

Table 2: Sucrose concentration of PLMs

\begin{tabular}{|c|c|c|c|c|c|c|}
\hline \multirow[b]{2}{*}{ S. no. } & \multirow{2}{*}{$\begin{array}{l}\text { Pediatric liquid medicament } \\
\text { (generic name) }\end{array}$} & \multicolumn{3}{|c|}{ Sugar content reading (in \%) } & \multirow[b]{2}{*}{ Mean (in \%) } & \multirow[b]{2}{*}{ Standard deviation } \\
\hline & & 1 & 2 & 3 & & \\
\hline 1 & Antipyretic (paracetamol) & 40.83 & 40.6 & 40.24 & 40.71 & 0.3 \\
\hline 2 & Antibiotic (amoxicillin-clavulanate) & 0 & 0 & 0 & 0 & 0 \\
\hline 3 & Antihistamine (cetirizine) & 14.1 & 15.2 & 15.75 & 14.64 & 0.84 \\
\hline 4 & Antitussive (dextromethorphan) & 38.28 & 38.4 & 38.63 & 38.34 & 0.18 \\
\hline 5 & Antiasthmatic (salbutamol) & 36.34 & 35.9 & 35.67 & 36.12 & 0.34 \\
\hline 6 & Anticonvulsant (phenytoin) & 48.75 & 48.25 & 47.93 & 48.5 & 0.41 \\
\hline 7 & Nutritional supplement (multivitamin) & 37.87 & 37.5 & 37.13 & 37.68 & 0.37 \\
\hline
\end{tabular}

Table 3: $\mathrm{pH}$ of pediatric liquid medicaments

\begin{tabular}{|c|c|c|c|c|c|c|}
\hline \multirow[b]{2}{*}{ S. no. } & \multirow{2}{*}{$\begin{array}{l}\text { Pediatric liquid medicament } \\
\text { (generic name) }\end{array}$} & \multicolumn{3}{|c|}{$\mathrm{pH}(10 \%)$} & \multirow[b]{2}{*}{ Mean } & \multirow[b]{2}{*}{ Standard deviation } \\
\hline & & 1 & 2 & 3 & & \\
\hline 1 & Antipyretic (paracetamol) & 5.98 & 6.17 & 6.24 & 6.07 & 0.13 \\
\hline 2 & Antibiotic (amoxicillin-clavulanate) & 4.65 & 4.44 & 4.36 & 4.54 & 0.15 \\
\hline 3 & Antihistamine (cetirizine) & 4.59 & 4.75 & 4.87 & 4.67 & 0.14 \\
\hline 4 & Antitussive (dextromethorphan) & 4.29 & 4.32 & 4.15 & 4.3 & 0.09 \\
\hline 5 & Antiasthmatic (salbutamol) & 4.21 & 4.27 & 4.19 & 4.24 & 0.04 \\
\hline 6 & Anticonvulsant (phenytoin) & 4.74 & 4.8 & 4.98 & 4.77 & 0.12 \\
\hline 7 & Nutritional supplement (multivitamin) & 3.99 & 4.07 & 4.19 & 4.03 & 0.1 \\
\hline
\end{tabular}

Table 4: Calcium dissolution potential of PLMs

\begin{tabular}{|c|c|c|c|c|c|c|c|}
\hline \multirow{2}{*}{$\begin{array}{l}\text { Pediatric liquid } \\
\text { medicament }\end{array}$} & \multicolumn{4}{|c|}{ Calcium present in syrup (Ppb) } & \multicolumn{3}{|c|}{ Calcium dissolution from syrup (Ppb) } \\
\hline & Begin & $1 \mathrm{~min}$ & $10 \mathrm{~min}$ & 8 hour & $1 \mathrm{~min}$ & $10 \mathrm{~min}$ & 8 hour \\
\hline Antipyretic & 360 & 413 & 520 & 1,080 & 53 & 160 & 720 \\
\hline Antibiotic & 480 & 649 & 933 & 3,360 & 169 & 453 & 2,880 \\
\hline Antihistamine & 0 & 161 & 458 & 1,290 & 161 & 458 & 1,290 \\
\hline Antitussive & 170 & 307 & 720 & 2,710 & 137 & 550 & 2,540 \\
\hline Antiasthmatic & 310 & 568 & 943 & 3,360 & 258 & 633 & 3,050 \\
\hline Anticonvulsant & 390 & 612 & 828 & 2,080 & 222 & 438 & 1,690 \\
\hline $\begin{array}{l}\text { Nutritional } \\
\text { supplement }\end{array}$ & 430 & 535 & 691 & 1,190 & 105 & 261 & 760 \\
\hline
\end{tabular}


An In Vitro Assessment of Cariogenic and Erosive Potential of PLMs

Table 5: Correlation between $\mathrm{pH}$ and calcium-dissolving capacity

\begin{tabular}{llllc}
\hline & & \multicolumn{3}{c}{ Calcium dissolution from syrup (Ppb) } \\
\cline { 3 - 5 } Pediatric liquid medicament & pH mean & $1 \mathrm{~min}$ & $10 \mathrm{~min}$ & 8 hour \\
\hline Antipyretic & 6.07 & 53 & 160 & 720 \\
Antibiotic & 4.54 & 169 & 453 & 2,880 \\
Antihistamine & 4.67 & 161 & 458 & 1,290 \\
Antitussive & 4.30 & 137 & 550 & 2,540 \\
Antiasthmatic & 4.24 & 258 & 633 & 3,050 \\
Anticonvulsant & 4.77 & 222 & 438 & 1,690 \\
Nutritional supplement & 4.03 & 105 & 261 & 760 \\
& & & & 7 \\
$N$ & & 7 & 7 & -0.4556 \\
Pearson correlation coefficient $(r)$ & & -0.5151 & -0.6170 & 0.3050 \\
$p$ value $^{\text {a }}$ & & 0.2369 & 0.1400 & \\
\hline
\end{tabular}

${ }^{a}$ Calculated with a significance of 0.05

stipulates that higher risk for dental diseases is associated with children having chronic conditions and who are taking medicines. ${ }^{3}$

The sucrose percentage in pediatric medicaments varies from 0 to $67 \%$. Pomorico et al. ${ }^{7}$ reported a sucrose presence of 5-54 $\mathrm{g} \%$ in 7 of the 10 samples used. Glucose is the other commonly identified sugar present in pediatric medicines. Brazilian studies also have reported glucose presence in several PLMs in the varying range of 2.10 and $40.19 \mathrm{~g} \%$. A similar study done by Subramaniam and Nandan ${ }^{3}$ stated that the sugar contents in PLMs range from 0.84 to $5.49 \mathrm{~g} \%{ }^{4}$ Sunitha et al. ${ }^{8}$ estimated the sucrose level is commonly used PLMs and it ranged from 7.2 to $77 \% \mathrm{wt} / \mathrm{vol}$. Passos et al. ${ }^{6}$ estimated the sucrose levels in PLMs based upon the frequency and duration of usage. The sucrose values for the medicaments prescribed once a day, twice a day, and 3-4 times a day, respectively, were $47.15 \pm 9.57 \%, 24.42 \pm 18.03 \%$, and 34.43 $\pm 14.83 \%(p<0.01)$.

In accordance with the above-mentioned studies, the current study sucrose content ranged from 0 to $48.25 \%$, confirming the fact that pharma companies are using sucrose indiscriminately.

Pediatric liquid medicaments contain acids in addition to sweetening agents which leads to dental erosion and the erosive potential can be evaluated under two parameters, these are the $\mathrm{pH}$ level of PLMs and tooth calcium dissolution potential of PLMs. ${ }^{5}$ The erosive potential of medicines was demonstrated by Weld GW as early as 1886 as mentioned in Girish et al. ${ }^{5}$

A study done by Babu et al. ${ }^{9}$ on the acidogenic nature of PLMs reported that $\mathrm{pH}$ ranged from 6.05 to 6.77 in the majority and theophylline has a basic pH of 7.71. A similar study done by Priya Subramanyam et al. ${ }^{3}$ evaluated the endogenous $\mathrm{pH}$ potential of PLMs which ranged from 3.70 to 7.04 .

An in vitro study was conducted by Passos et al. ${ }^{6}$ on the longterm used PLMs used by children for SC and the $\mathrm{pH}$ (mean \pm SD) measured in this study was $5.89 \pm 2.02$ and the highest mean sucrose content (36.32\%) was observed in respiratory drugs. A similar study was conducted by Ruchi et al. ${ }^{11}$ on 94 pediatric medicines for assessing the erosive potential concluding an endogenous $\mathrm{pH}$ of $<5.5$ for 55 (59\%) formulations.

In the present study, the $\mathrm{pH}$ of seven commonly used PLMs ranged from 4.07 to 6.17 out of which $80 \%$ of PLMs ranged from 4.07 to 4.9 that is acidic $\mathrm{pH}$ which agrees with the preceding studies on PLMs which affirms that low $\mathrm{pH}$ is the main etiological factor behind dental caries and dental erosion.
The main concept of the dissolution potential of PLM is due to chelating agents present in PLMs leading to loss of calcium in dental elements irrespective of $\mathrm{pH}^{10}$ In the present study, calcium dissolution of PLMs after 1 minute ranged from $80 \mathrm{Ppb}$ (salbutamol) to $170 \mathrm{Ppb}$ (paracetamol). After 10 minutes, it ranged from 150 $\mathrm{Ppb}$ (dextromethorphan) to $300 \mathrm{Ppb}$ (paracetamol). After 8 hours, it ranged from $720 \mathrm{Ppb}$ (paracetamol) to 3,050 Ppb (salbutamol). Calcium dissolution is maximum after an 8 hour interval followed by a 10 minute and 1 minute interval. It is maximum in salbutamol which is in correlation with the study done by Girish et al. ${ }^{10} \mathrm{~A}$ similar study done by Nankar et al. ${ }^{1}$ appraised the erosive potential of PLMs concluding the highest and the lowest calcium dissolution observations in Syr combiflam $(295.86 \mathrm{mg} / \mathrm{mL}$ ) and Syr orofer (25.51 $\mathrm{mg} / \mathrm{mL}$ ). In the present study, no statistically significant correlation was observed between the PLMs $\mathrm{pH}$ and the calcium dissolution potential.

For the determination of calcium dissolution potential, previous studies have adopted atomic absorption spectrometry (AAS) but in the present study, ICP-MS was used which is far superior to the AAS. The main admirable advantages of ICP-MS are:

- Detection limits are 10 to 100 times superior to those of Inductively Coupled Plasma Atomic Emission Spectroscopy (ICP-AES) and AAS.

- In a time span of around 2 minutes, an analysis of 25 elements in duplicate can be achieved.

- Ability to provide elemental isotopic ratio information.

- The techniques can be customized specifically for the sample form or type of analyte using the differing types of ICP-MS instruments combined with various types of sample introduction.

- Large linear dynamic working range.

- The values obtained in this method are technically more accurate, measured in Ppb, whereas in AAS it is in Ppm.

With the advent of technology in material science, different compounds present in elemental form can be traced and quantified effectively to one billionth part which increases the accuracy and importance of this study.

The indiscriminate use of liquid medicines in young children can increase the risk for the development of dental erosion and dental caries. ${ }^{13}$ Due to ill-effects associated with these preparations, an exhaustive subjective assessment to check their cariogenic and erosive potential must be embraced. ${ }^{5}$ Pharma industries 
should decrease the indiscriminate use of sugars, such as, sucrose in pediatric syrups and should think about the usage of artificial sweeteners, such as, xylitol, etc., without affecting the stability of active ingredients in the syrup.

\section{Conclusion}

Present in vitro study concluded that

- The highest SC was present in Syp phenytoin $48.25 \%$ and lowest in Syp amoxicillin-clavulanate.

- $\mathrm{pH}$ was lowest in multivitamin syrup (4.07) and highest in Syp paracetamol (6.17).

- Calcium dissolution potential was highest in Syp salbutamol (3,050 Ppb) and lowest in Syp paracetamol (720 Ppb).

- The relationship between the pH of PLMs and calcium dissolution was not found to be statistically significant.

In conclusion, out of the tested PLMs, Syp phenytoin can be regarded as the medicament with the highest cariogenic potential, Syp salbutamol with the highest erosive potential, and Syp paracetamol as the medicament with least cariogenic and erosive potential.

\section{Clinical Significance}

Considering syrups that have high cariogenic and erosive potential, greater knowledge about the detrimental effects of these drugs should direct us to evolve effective programs to alert parents to follow proper practices for oral hygiene or to go with alternative drugs without the detrimental effects.

\section{References}

1. Nankar M, Walimbe H, Bijle MN, et al. Comparative evaluation of cariogenic and erosive potential of commonly prescribed pediatric liquid medicaments: an in vitro study. J Contemp
Dent Pract 2014;15(1):20-25. DOI: 10.5005/jp-journals10024-1481.

2. Babu KG, Doddamani GM, NaikLK, et al. Pediatric liquid medicamentsare they cariogenic? an in vitro study. J Int Soc Prev Community Dent 2014;4(2):108-112. DOI: 10.4103/2231-0762.137637.

3. Subramaniam P, Nandan N. Cariogenic potential of pediatric liquid medicaments-an in vitro study. J Clin Pediatr Dent 2012;36(4):357-362. DOI: $10.17796 / j c p d .36 .4 . n t 11584612462$ t84.

4. Zhao D, Tsoi JK, Wong HM, et al. Paediatric over-the-counter (OTC) oral liquids can soften and erode enamel. Dent J 2017;5(2):17-29. DOI: 10.3390/dj5020017.

5. Babu KG, Rai K, Hedge A. Pediatric liquid medicaments-do they erode the teeth surface? an in vitro study: part I. J Clin Pediatr Dent 2008;32(3):189-194.

6. Passos IA, Sampaio FC, Martínez CR, et al. Sucrose concentration and $\mathrm{pH}$ in liquid oral pediatric medicines of long-term use for children. Rev Panam Salud Publica 2010;27(2):132-137. DOI: 10.1590/S102049892010000200007.

7. Pomarico L, Czauski G, Portela MB, et al. Cariogenic and erosive potential of the medication used by HIV-infected children: $\mathrm{pH}$ and sugar concentration. Community Dent Health 2008;25(3):170-172.

8. Sunitha S, Prashanth GM, Chandu GN, et al. An analysis of concentration of sucrose, endogenous $\mathrm{pH}$, and alteration in the plaque $\mathrm{pH}$ on consumption of commonly used liquid pediatric medicines. J Indian Soc Pedod Prev Dent 2009;27(1):44-48. DOI 10.4103/0970-4388.50817.

9. Babu KG, Rai K, Hegde A. pH of medicated syrups-does it really matter?-an in vitro study: part-II. J Clin Pediatr Dent 2008;33(2):137142. DOI: 10.17796/jcpd.33.2.q5280t37448827v0h.

10. Subramaniam P, Kumar K. Cariogenic potential of medications used in treatment of children with HIV infection. Special Care Dentist 2014;34(3):127-130. DOI: 10.1111/scd.12041.

11. Arora R, Mukherjee U, Arora V. Erosive potential of sugar free and sugar containing pediatric medicines given regularly and long term to children. Indian J Pediatr 2012;79(6):759-763. DOI: 10.1007/s12098011-0543-5.

12. Kiran KJ, Vinay C, Uloopi KS, et al. Erosive potential of medicated syrups on primary teeth: an in vitro comparative study. Br J Med Med Res 2014;5(4):525-532. DOI: 10.9734/BJMMR/2015/13434. 